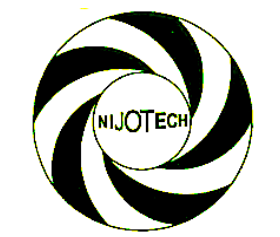

Nigerian Journal of Technology (NIJOTECH)

Vol. 39, No. 2, April 2020, pp. 607 - 612

Copyright@ Faculty of Engineering, University of Nigeria, Nsukka

Print ISSN: 0331-8443, Electronic ISSN: 2467-8821

www.nijotech.com

http://dx.doi.org/10.4314/njt.v39i2.32

\title{
APPRAISAL OF ENVIRONMENTAL SUSTAINABILITY STUDIES IN THE QUANTITY SURVEYING CURRICULUM
}

\author{
A. Nazif ${ }^{1, *}$, A. K. Mustapha ${ }^{2}$ and D. Ocheme ${ }^{3}$

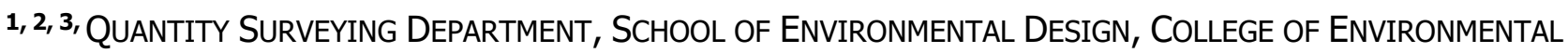 \\ StUdiES, KADUNA PolyteChnic, Kaduna StaTE, NIGERIA \\ E-mail addresses: 1 aminanazif@yahoo.co.uk, ${ }^{2}$ zeemnina@yahoo.com, \\ 3 davidson914life@gmail.com
}

\begin{abstract}
The construction industry requires professionals that are environmentally sensitive to sustain the built environment for future generation. This is necessary due to the rising environmental degradation from various construction activities. Tertiary institutions could be the appropriate platform to instil these ideas in aspiring construction professionals. This study assessed Quantity Surveying (QS) curriculum of Polytechnics to examine the courses taught and to assess whether there are courses in the curriculum that are related to environmental sustainability studies. Also, questionnaires administered to lecturers and students of QS departments was used to examine the concept and awareness of environmental sustainability taught in the institution. The study established that generally, taught courses in QS departments of Polytechnics have little or no environmental sustainability factored into them. Furthermore, cumulative mean and regression analysis were used to evaluate the data obtained from the questionnaire. The analysis established that the respondents affirmed that the QS curriculum does not create awareness of environmental sustainability, having a cumulative mean score of 2.04 for lecturers and 2.28 for students which is within the cut-off point of 1.5 to 2.5 (Disagree). Based on the regression analysis, it was established that the correlation between the lecturers' and the students' responses was significant having a $R$ result of 0.95. The regression analysis explicated that the lecturers can explain the students' views having a $R^{2}$ value of 0.90 . The review of $Q S$ curriculum to include environmental sustainability studies is paramount in producing $Q S$ professionals that are environmentally inclined in training.
\end{abstract}

Keywords: Environmental Sustainability, Quantity surveying, Higher institutions and Curriculum

\section{INTRODUCTION}

Saving the earth is a collective responsibility of all construction experts. The construction industry consumes substantial amount of natural resources and energy for construction projects [1]. Globally, the construction sector utilizes $20 \%$ of energy produced [2]. This can lead to the depletion of natural resources for construction activities. It has been established that built environment experts have inadequate understanding of the benefits of sustainable construction [3]. This has over the years contributed to the increase in environmental degradation. Protecting the environment requires relevant knowledge, innovative techniques and responsible practices. With the increasing complexity of environmental issues, education in Nigeria should focus on instilling environmental responsibility and accountability [4].

"Environmental Sustainability" is becoming an important phenomenon in the built environment. In view of this, it has become necessary for all construction experts to be knowledgeable in this aspect. In a previous study it was opined that to produce construction graduates who meet this need, it is necessary to retool programmes so that they incorporate environmentally friendly philosophies and techniques [5]. According to another study, environmentally responsive education can easily be

* Corresponding author, tel: +234 8120020020 
integrated into programmes either by incorporating this idea into existing courses or by creating new courses that focuses primarily on sustainable ideas [6].

Quantity surveyors are saddled with the responsibility of being accountants and cost advisers of the construction industry. Therefore, there is the need for Quantity surveyors to understand the vulnerability of the natural resources available for construction projects and find solutions on how to safeguard and sustain the environment for future generation [7]. This paramount orientation can start from educational institutions. This can be done by integrating environmental sustainability education in the curricula of higher institutions [8]. This would go a long way in producing construction experts that are conscious of the environment and that would be able to give reputable advice on the most cost effective as well as environmentally friendly alternatives to construction [9]. All construction experts should see environmental sustainability as a paramount issue to be addressed soonest. Imagine a world where construction industry cost professionals are environmentalist. Whatever materials used in the built environment would be environmentally friendly and at affordable cost.

In Nigeria, The National Board for Technical Education (NBTE) has the duty of establishing the curriculum for Polytechnics. The NBTE curricula is the benchmark for Nigerian Polytechnics. The curriculum was revised in 2008 with the collaboration of United Nations Education and Science Organization (UNESCO) [10]. This study focused on assessing the Quantity Surveying (QS) Curriculum of Polytechnics in Nigeria. This was done by evaluating the curriculum to check for courses related to environmental sustainability. Subsequently questionnaires were administered to both lecturers and students of the department of Quantity Surveying to understand their concept and awareness of environmental sustainability.

\section{MATERIALS AND METHODS}

\subsection{Data Collection and Analysis}

The NBTE QS curriculum was screened and all courses offered by the QS department were examined. This was done to assess whether courses for environmental sustainability were taught from Ordinary National Diploma (OND) to Higher National Diploma (HND) levels. Additionally, questionnaires were assigned to lecturers and students of the QS department of Kaduna Polytechnic to assess their understanding of the concept and awareness of environmental sustainability. Subsequently, regression analysis was used to establish the relationship between the concept and awareness of environmental sustainability studies of the lecturers and students.

The curriculum is divided into OND1 and OND2 with each having 2 semesters. Then, the HND is divided into HND1 and HND2 each having 2 semesters as well. Table 2 outlines courses offered from OND1 to HND2. Table 2 displays that each level had at least 19 courses comprising of first and second semester, it was established that none of the courses for the whole session had any course related to environmental sustainability.

There is a general shortage of designated courses related to environmental sustainability in the QS curricula of NBTE. Recent trend in construction activities would require environmental sustainability education and practices to be a specialized program. This will adequately prepare future professionals on the need for any environmental issues on/off sites. The data was collected from the respondent through the help of a structured questionnaire. A total of 150 questionnaires were distributed having 30 questionnaires for lecturers and 120 for students. However, 118 questionnaires were returned and used for this study 20 from lecturers and 98 from students. The questionnaires for the students focused on students in HND students, this was due to their longer years in the Polytechnics.

The statistical mean scores and standard deviation was used to analyse the Likert's five - point questionnaire while the frequency count and simple percentage was used to analyse respondents' characteristics. Cumulative mean score was used in analysing the hypothesis.

The formula for mean $(\Sigma)=\frac{\sum f x}{\Sigma f}$ Where: $f x=$ Total frequency and $f=$ Frequency 
Table 1: Courses Offered from OND to HND

\begin{tabular}{ll}
\hline Levels & Courses \\
\hline Ordinary National Diploma 1 & Algebra and Trigonometry, Use of English and Communication \\
& I, Principles in Surveying I and II, Technical Drawing, \\
& Introduction to Measurement and Measurement of Building \\
& works, Basic Engineering Science, Properties of Materials I, \\
& Wood, Block-laying, and Concreting Workshop Practice, \\
& Principles of Economics, Principles of Accounting, Building \\
& Construction I and II, Entrepreneurship Development I, \\
& Citizenship Education, Principles of Law and Introduction to \\
& Engineering Geology I. \\
Ordinary National Diploma 2 & Calculus, Statistics, Use of English and Communication II, \\
& Project management, Building Services, Building \\
& Measurement and Specification II, Principles of Engineering \\
& Measurement, Maintenance Technology I, Programing \\
& Concepts using Visual Basics, SIWES, Project I, Strength of \\
& Materials and Structures I, Workshop Practice and \\
& Technology, Principles of Construction Economics I and II, \\
& Tendering and Estimating I and II, Introduction to Soil \\
& Mechanics I, Basic Principles of Architectural Design \& \\
& Drawing I, Building Construction III, Introduction to \\
& Computing using Packages \\
& Courses
\end{tabular}

Higher National Diploma 1

Advanced Measurement of Construction Works I and 11, Construction Economics I and II, Construction Management I and II, Construction Technology I and II, Tendering and Estimating I and II, Services I and II, Contract Law and Arbitration , Architectural Design and Drawing 1, General Studies - International Relations 2, Conditions of Contract, Measurement of Civil Engineering Works I, Computer Application in Project Management, Technical Report Writing.

Higher National Diploma 2 Advanced Measurement of Construction Works III and IV, Construction Economics III, Measurement of Heavy Engineering Works, Financial Management I, Construction Technology III and IV, Marketing, Tendering and Estimating III and IV, Professional Practice and Procedures I and II, Valuation and Final Accounts Procedures 1 and II, Measurement of Civil Engineering Works II, Maintenance Technology and Management 1, Research Methodology 1, Estate Management and Valuation I, and Project 1.

Table 2: Five Likert Rating Scale

\begin{tabular}{llllll}
\hline & Strongly Agree & Agree & Undecided & Disagree & $\begin{array}{l}\text { Strongly } \\
\text { Disagree }\end{array}$ \\
\hline $\begin{array}{l}\text { Grade Point } \\
\text { Range }\end{array}$ & 5 & 4 & 3 & 2 & 1 \\
& $4.5-5.4$ & $3.5-4.4$ & $2.5-3.4$ & $1.5-2.5$ & $0.5-1.4$
\end{tabular}




\subsection{Regression Analysis}

The relationship between the responses of the lecturers and students was analyzed using correlation analysis. Besides, correlation involves dealing with relationships between variables. Consequently, correlation coefficient $(r)$ measures the linear association between two variables. Usually, values of the correlation coefficient are between -1 and +1 . A correlation coefficient of +1 identifies that two variables are significantly related in a positive linear logic; a correlation coefficient of -1 identifies that two variables are significantly related in a negative linear sense, and a correlation coefficient of 0 indicates that there is no linear relationship between the two variables [11].

\subsubsection{Linear Regression Analysis}

The general form of LR analysis is as follows:

$Y_{i}=\beta_{0}+\beta_{1} X_{1 i}+\varepsilon_{i}$

Where $Y$ is the dependent variable (predictant), $\beta_{0}$ is a constant coefficient, $\beta_{1}$, is referred to as regression coefficients while $X_{1}$, (predictor) is the independent variable and $\varepsilon$ is the residual error (difference between observed and predicted values) [11].

\subsubsection{Coefficient of Determination $\left(\mathbf{R}^{2}\right)$}

$R^{2}$ is used to signify how well the model results fit to the observed data points; it can also be used to indicate the similarity between the model tendency and the observed concentration [11].

$\mathrm{R}^{2}=\left[\frac{\sum_{i=1}^{n}\left(\boldsymbol{O}_{i}-\overline{\boldsymbol{O}}\right)^{2} \cdot\left(\boldsymbol{P}_{i}-\bar{P}\right)}{n \cdot \sigma_{0} \cdot \sigma_{p}}\right]^{2}$

Where, $\mathrm{n}$ is total number of annual measurements, $\mathrm{P} i$ is predicted values, $\mathrm{O} i$ is observed values, $\bar{O}$ is the mean observed values, $\bar{P}$ is mean of the predicted values, $\sigma_{p}$ is standard deviation of the predicted values, and $\sigma_{o}$ is standard deviation of the observed values.

\section{RESULTS AND DISCUSSION}

\subsection{Questionnaire analyses}

Research Question 1: Does the NBTE QS curriculum impart the concept of environmental sustainability?

Research Question 2: Does the NBTE QS curriculum create awareness of environmental sustainability?
The result for Research Question 1 and 2 were acquired through questionnaires. The sample of the questionnaires is attached in the appendices Based on Table 3, the mean of the lecturers' and students were calculated using the Likert scale based on the individual responses to the questionnaire allocated to them. The analysis showed that the respondents disagree th at the NBTE QS curriculum impart the concept of environmental sustainability to students. The cumulative mean score for the research question 1 was 2.45 for lecturers and 2.32 for students. This is within the cut-off point of 1.50 to 2.50 , as shown in the Likert Rating Scale range in Table 2. Also, the analysis showed that the respondents disagree that the NBTE QS curriculum creates awareness of environmental sustainability. Accordingly, the cumulative mean score for Question 2 regarding the awareness of Environmental sustainability was 2.04 for lecturers and 2.28 for students which is also within the cut-off point of 1.50 to 2.50 . The result shows that both lecturers' and students disagree that the NBTE QS curriculum creates awareness of environmental sustainability to students.

Furthermore, correlation was carried out to understand the relationship between the lecturers and students' responses as shown in Table 4. The parameters used for the Linear regression analysis for both concept and awareness of environmental sustainability were the mean of Lecturers' and Students from Table 3. For the concept of environmental sustainability, it was realised that the correlation result was 0.66 establishing that there is a relationship between the response of the students and the lecturers. However, when regression analysis was carried out to recognize the influence of the ideas to the students as shown in Figure 1, it was established that the ideas of the lecturers can explain the ideas of the students by 0.44 which is not significant, this is associated with the $P$-value result of 0.153 which is relatively high, this buttresses the reason why the $R^{2}$ value is low. This establishes that both responses are independent of each other.

For the awareness of environmental sustainability, it was established that the correlation between the lecturers' and the students' responses was significant having a $R$ result of 0.95 . The linear regression chart in Figure 2 which gave a $R^{2}$ of 0.9 revealed that the lecturers' responses can explain

Vol. 39, No. 2 April $2020 \quad 610$ 
that of the students, that is the level of awareness of environmental sustainability of the lecturer explains that of the student with $90 \%$ certainty.
This is also associated with the P-value result of 0.004 which is low, this supports the reason why the $R^{2}$ value is high and significant.

Table 3: Mean Result of the Concept and Awareness of Environmental Sustainability

\begin{tabular}{lllll}
\hline & Concept & \multicolumn{3}{c}{ Awareness } \\
\hline & Mean (Lecturers) & Mean (Students) & Mean (Lecturers) & Mean (Students) \\
\hline \multirow{4}{*}{ Mean score } & 4.00 & 2.23 & 1.85 & 1.92 \\
& 1.25 & 2.08 & 2.10 & 2.08 \\
& 1.30 & 2.01 & 2.85 & 3.29 \\
Cumulative & 1.80 & 1.94 & 1.50 & 1.89 \\
score & 2.40 & 1.95 & 1.60 & 1.90 \\
\hline
\end{tabular}

Field work (2018)

Table 4: Regression Analyses Results

\begin{tabular}{lll}
\hline Analyses & Concept & Awareness \\
\hline Linear regression model & $\mathrm{Y}=1.1945 x-0.3232$ & $\mathrm{Y}=0.8549 x+0.0969$ \\
$\mathrm{R}$ & 0.66 & 0.95 \\
$\mathrm{R}^{2}$ & 0.44 & 0.90 \\
$\mathrm{P}$-value & 0.153 & 0.004 \\
\hline
\end{tabular}

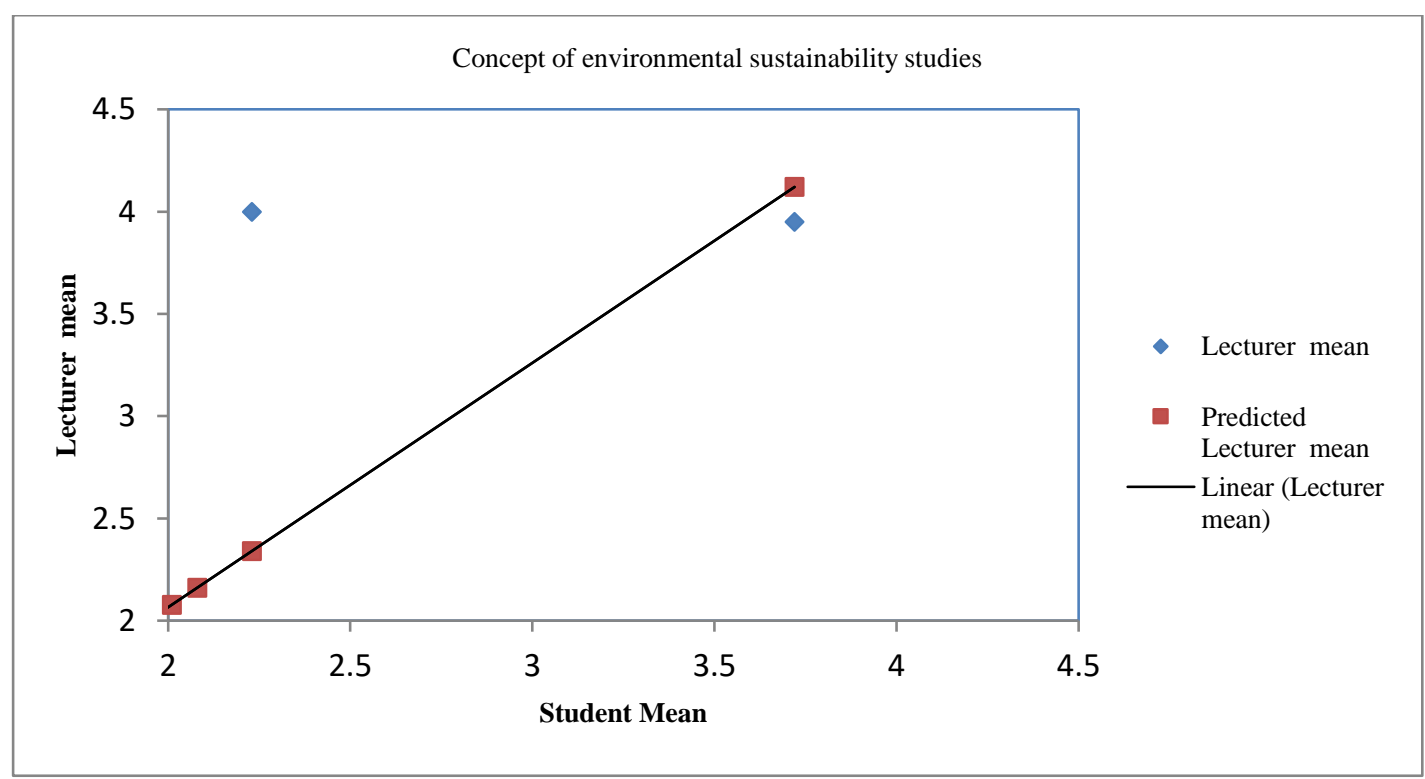

Figure 1 Linear regression model of concept of environmental sustainability 


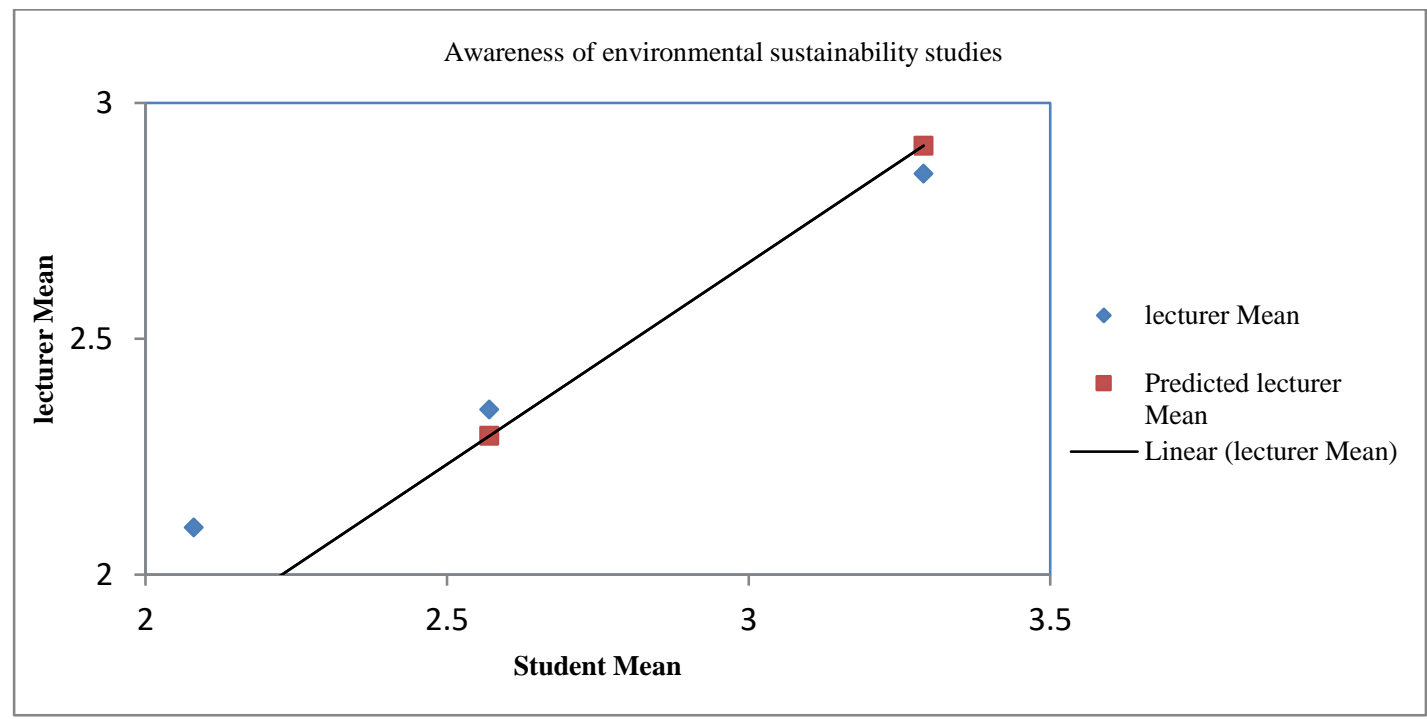

Figure 2 Linear regression of awareness of environmental sustainability

\section{CONCLUSION}

The study showed that the current NBTE QS curriculum does not impart the concept nor create the awareness of environmental sustainability to Polytechnic students. The environmental sustainability studies should be incorporated and integrated into the training curriculum of construction professional to address environmental issues. This will aid in producing Quantity Surveyors with profound knowledge in tackling environmental challenges.

\section{REFERENCES}

[1] Hussin, J. M., Rahman, I. A., and Memon, A. H. "The Way Forward In Sustainable Construction: Issues And Challenges". International Journal of Advances in Applied Sciences, 2(1), 15-24, 2013.

[2] Alrashed, F., Asif, M., and Burek, S. "The Role Of Vernacular Construction Techniques And Materials For Developing Zero-Energy Homes In Various Desert Climates". Buildings, 71$), 17$, 2017.

[3] Ding, G. K. "Sustainable Construction -The Role Of Environmental Assessment Tools". Journal of Environmental Management, 86(3), 451-464, 2008.

[4] Robinson, J. "Squaring The Circle? Some Thoughts On The Idea Of Sustainable Development". Ecological Economics, 48(4), 369-384, 2004.

[5] Tinker, A., \& Burt, R. "Greening The Construction Curriculum". International Journal of
Construction Education and Research, 9(2), 2633, 2004.

[6] Thorpe, T. and Mead, S."Project-specific web sites: Friend or foe? "Journal of construction engineering and management, 127(5), 406-413, 2001.

[7] Opoku, A. and Peter Guthrie, P. "Education for Sustainable Development in the Built Environment". International Journal of Construction Education and Research, 14:1, 13, DOI: $10.1080 / 15578771.2018 .1418614$, 2018.

[8] Martínez, M. P. B., Molina, R. E. F. and Díaz, C. A. S. "Sustainable Education and Education for Sustainability: Importance of Sustainable Development in Higher Education". International Conference on the Future of Education. Florence Italy, 2018.

[9] Opoku, A., \& Egbu, C. "Students' Perspectives On The Relevance Of Sustainability Literacy In A Postgraduate Built Environment Program". International Journal of Construction Education and Research, 14(1), 46-58, 2018.

[10] Ikpe, U. "Vocational-Technical Education In Nigeria: A Review". Global Journal of Educational Research, 9(1-2), 33-39, 2010.

[11] Hox, J. J., Moerbeek, M. and Van de Schoot, R. Multilevel Analysis: Techniques and Applications $3^{\text {rd }}$ Edition. Routledge Press. ISBN 1317308689, 2017. 